\title{
Association between the social support for mothers of patients with eating disorders, maternal mental health, and patient symptomatic severity: A cross-sectional study
}

\author{
Atsurou Yamada ${ }^{1}$, Fujika Katsuki ${ }^{2}$ (D), Masaki Kondo ${ }^{1}$, Hanayo Sawada ${ }^{2}$, Norio Watanabe ${ }^{3}$ and Tatsuo Akechi ${ }^{1}$
}

\begin{abstract}
Background: Although caregivers of patients with eating disorders usually experience a heavy caregiving burden, the effects of social support on caregivers of patients with eating disorders are unknown. This study aimed to investigate how social support for mothers who are caregivers of patients with an eating disorder improves the mothers' mental status and, consequently, the symptoms and status of the patients.

Methods: Fifty-seven pairs of participants were recruited from four family self-help groups and one university hospital in Japan. Recruitment was conducted from July 2017 to August 2018. Mothers were evaluated for social support using the Japanese version of the Social Provisions Scale-10 item (SPS-10), self-efficacy using the General Self-Efficacy Scale, loneliness using the University of California, Los Angeles Loneliness Scale, listening attitude using the Active Listening Attitude Scale, family functioning using the Family Assessment Device, depression symptoms using the Beck Depression Inventory (Second Edition), and psychological distress using the Kessler Psychological Distress Scale. Patients were evaluated for self-esteem using the Rosenberg Self-Esteem Scale, assertion using the Youth Assertion Scale, and their symptoms using the Eating Disorder Inventory. We divided the mothers and patients into two groups based on the mean score of the SPS-10 of mothers and compared the status of mothers and patients between the high- and low-scoring groups.
\end{abstract}

Results: High social support for mothers of patients with eating disorders was significantly associated with lower scores for loneliness and depression of these mothers. We found no significant differences in any patient scores based on mothers' level of social support.

Conclusions: For patients with eating disorders, social support for a caregiver cannot be expected to improve their symptoms, but it may help prevent caregiver depression and loneliness.

Keywords: Caregiver, Depression, Eating disorders, Listening attitude, Loneliness, Psychological distress, Self-efficacy, Social support

\footnotetext{
* Correspondence: katsuki@med.nagoya-cu.ac.jp

${ }^{2}$ Department of Psychiatric and Mental Health Nursing, Nagoya City

University Graduate School of Nursing, 467-8601, 1 Kawasumi, Mizuho-cho,

Mizuho-ku, Nagoya, Japan

Full list of author information is available at the end of the article
}

C The Author(s). 2021 Open Access This article is licensed under a Creative Commons Attribution 4.0 International License, which permits use, sharing, adaptation, distribution and reproduction in any medium or format, as long as you give appropriate credit to the original author(s) and the source, provide a link to the Creative Commons licence, and indicate if changes were made. The images or other third party material in this article are included in the article's Creative Commons licence, unless indicated otherwise in a credit line to the material. If material is not included in the article's Creative Commons licence and your intended use is not permitted by statutory regulation or exceeds the permitted use, you will need to obtain permission directly from the copyright holder. To view a copy of this licence, visit http://creativecommons.org/licenses/by/4.0/. The Creative Commons Public Domain Dedication waiver (http://creativecommons.org/publicdomain/zero/1.0/) applies to the data made available in this article, unless otherwise stated in a credit line to the data. 


\section{Plain English summary}

The effects of social support on caregivers of patients with eating disorders are unknown. This study aimed to investigate how social support for mothers who are caregivers of patients with an eating disorder improves the mothers' mental status and, consequently, the symptoms and status of the patients. Fifty-seven pairs of participants were recruited from four family self-help groups and one university hospital in Japan. Mothers were evaluated for social support, self-efficacy, loneliness, listening attitude, family functioning, depression symptoms, and psychological distress. Patients were evaluated for self-esteem, assertion, and symptoms of eating disorder. We compared the status of mothers and patients between the high and low social support groups based on the mothers' mean score on the Japanese version of the Social Provisions Scale-10 item. High social support for mothers was significantly associated with lower scores for loneliness and depression. There were no significant differences in any patient scores based on mothers' level of social support. Social support for a caregiver of patients with eating disorders may help prevent caregiver depression and loneliness, but cannot be expected to improve patients' symptoms.

\section{Background}

Caregivers of patients with eating disorders usually experience a heavy caregiving burden, and are at risk of having poor mental health status [1] and a low quality of life [2]. The mean Hamilton Anxiety and Depression Scale score for 246 caregivers of patients with eating disorders was above the threshold for both anxiety and depression [3]. The level of depression and anxiety in caregivers, especially in mothers, was much higher than in a non-caregiver group [4]. Conversely, stress, anxiety and depression of caregivers of patients with eating disorders were all under the threshold on the Depression Anxiety Stress Scale [5]. According to a systematic review on eating disorders, eight studies that used the Hamilton Anxiety and Depression Scale reported that the levels of anxiety were high but the levels of depression were under the threshold [6]. Moreover, three studies using the Depression Anxiety Stress Scale reported that levels of anxiety and depression were normal and levels of stress were mild to severe [6]. Therefore, although there were variations in reports, caregivers' anxiety and depression were generally high.

Previous studies have shown that providing social support for caregivers reduces their distress levels and enhances their mental health. Social support includes affective support and instrumental support. For example, a lack of affective support was significantly associated with worsened mental health status, and affective support was significantly associated with decreased severity of the patients' symptoms from the family's perspective [1]. Social support also includes spousal support. Among mothers of children with eating disorders, being married was shown to be a protective factor of caregiver burden, and the authors remarked that this protective function may due to spousal support [7]. However, there are also reports claiming that social support is not related to mental health or decreased psychological distress. For example, Dimitropoulos et al. reported that social support was related to family functioning but not to scores on the General Health Questionnaire [8]. Family functioning is the interaction of family members in a family environment, including attachment, parenting style, communication, and conflict [9]. Coomer et al. reported social support was not a predictor of burden or psychological distress among caregivers of people with eating disorders; rather, expressed emotion and caregivers' needs were predictors of burden, and maladaptive coping was a predictor of psychological distress. However, they measured social support with Social Support Questionnaire 6, which is very general and affective in nature, and they stated that instrumental social support may be a predictor of burden and stress [10].

In summary, although previous reports have not agreed, social support may reduce psychological distress or improve mental health in caregivers of patients with eating disorders and it appears to be associated with lower accommodating behaviors and improved family functioning. Moreover, previous reports have also not agreed on whether social support reduces the severity of patients' symptoms. We hypothesized that caregivers with more social support have less psychological distress and better family functioning and behaviors, and that patients have fewer symptoms than those with caregivers who have less social support.

Regarding caregivers, this study targets only mothers in consideration of the homogeneity of the subjects because it has been reported that mothers have a higher burden than fathers $[7,8,11]$.

This study specifically aimed to investigate how social support for mothers who are caregivers of patients with eating disorders improves their mental status and, consequently, the symptoms and status of the patients. First, we aimed to investigate the association between mothers' support status and distress and associated factors (e.g., self-efficacy, loneliness, listening attitude, depression, and psychological distress). The reason for assessing mother's listening attitude in this study is that mothers with social support can afford to listen to the patient well, which may affect the patient's symptoms. Second, we aimed to investigate the association between mothers' support status and patients' symptoms and associated factors (e.g., self-esteem, loneliness, selfassessed assertion, family functioning, and eating disorder symptoms) from the patients' point of view. 


\section{Methods}

\section{Participants}

Participants were patients with an eating disorder and their mothers. Our recruitment took place in four family self-help groups for patients with eating disorders and in one university hospital in Japan. Family self-help group is an organization in which families and patients with eating disorders participate and regularly hold meetings and lectures to support each other. Recruitment was conducted from July 2017 to August 2018. At the selfhelp group lectures, we invited participants from four locations: Hokkaido, Chiba, Fukui, and Nagoya, all in Japan. Each lecture was attended by approximately 50 family members of patients. The purpose of the study was explained via instructions attached to a questionnaire to patients and their mothers who were interested in the study. Subsequently, the questionnaires for mothers and patients were distributed at home via postal mail to those who were willing to take part in the survey. For outpatients and inpatients in the hospital, the researcher provided instructions to the patient and mother who were judged by the patient's doctor to meet the inclusion criteria and were interested in the study. Next, the researcher handed them the self-report rating scale questionnaire. For mothers, the inclusion criteria were: aged between 30 and 85 years; mothers of patients who met the patient inclusion criteria. For patients, the inclusion criteria were: being a patient who had been confirmed by researchers to be clinically diagnosed with an eating disorder by a physician or psychiatrist in a hospital; aged between 16 and 50 years. We emphasize that we did not distinguish among specific eating disorders (e.g., anorexia nervosa and bulimia nervosa), but rather included patients with any type of eating disorder.

This study was approved by the Ethics Review Committee of Nagoya City University Graduate School of Medical Sciences, Japan (Ref: No 60-17-0001), and was conducted in accordance with the principles of the Declaration of Helsinki. Written informed consent was obtained from participants, and we have taken the necessary steps to ensure that all participants remained anonymous.

\section{Procedure}

We gave participants a leaflet with an explanation of the purpose and procedure of the study. After receiving permission from patients' mothers and their home addresses, we mailed the questionnaires to their homes. They were effectively enrolled in the study only when their completed questionnaires were returned. As described below, the questionnaire comprised questions on participants' basic sociodemographic characteristics as well as questions from the Japanese version of the Social Provisions Scale-10 item (SPS-10), the University of California, Los Angeles Loneliness Scale (ULS), the Beck
Depression Inventory (BDI-II), and the Kessler Psychological Distress Scale (K6), which were used to evaluate participants' loneliness, depression, and anxiety levels.

\section{Outcome measures for mothers of patients with an eating disorder \\ Basic characteristics}

In this study, we used the following to analyze mothers' basic sociodemographic characteristics: (1) age, (2) patient's eating disorder duration, (3) whether the patient (i.e., the daughter) receives medical care (if yes, for how many years), (4) whether the mother receives counseling (if yes, for how many years), (5) whether the mother has had an eating disorder, (6) whether the mother feels that she is cooperating with the father (if there is one) in handling the patient (yes, no, neither, not applicable), (7) whether the mother participates in a family self-help group (if yes, for how many years).

\section{The social provisions Scale-10 item (SPS-10)}

Mothers' support status was evaluated using the Japanese version translated from the SPS-10, which is a shortened version of the Social Provisions Scale (SPS) created by Cutrona and Russell [12] and was developed by Iapichino et al. in Italian [13]. With permission from Iapichino et al., we created a Japanese version of the SPS-10 and described its development in another article [14]. The SPS-10 consists of 10 items and retains the following five of the six original SPS subscales: attachment (emotional support), social integration, reassurance of worth, reliable alliance (material support), and guidance. In the original SPS, each subscale has four items: two positively worded items describing the presence of a type of support, and two negatively worded items assessing the absence of a type of support. The SPS-10 has only negatively worded items, and the total score ranges from 10 to 40 . A higher total score indicates stronger perceived provision of social support. The Cronbach's $\alpha$ of the original Italian version was .809 [13], and in this study, it was $\alpha=.897$.

\section{General self-efficacy scale (GSES)}

To assess mothers' self-efficacy, we used the GSES developed by Sakano et al. [15, 16]. The GSES comprises three subscales and 16 items: aggressive behavior (7 items), anxiety about failure (5 items), and social positioning of ability (4 items). Each item was scored as 0 or 1. The higher the score, the higher the general selfefficacy. The Cronbach's $\alpha$ of this study was $\alpha=.837$.

\section{University of California, los Angeles loneliness scale (ULS)}

To assess mothers' loneliness, we used the Japanese version (by Moroi) [17] of the ULS developed by Russell et al. [18]. The ULS is a 20-item scale, and each item was scored from 1 to 4 ; the higher the score, the 
stronger the loneliness. The Cronbach's $\alpha$ of the Japanese version was .885 [19]. We obtained the author's permission to use this scale. The Cronbach's $\alpha$ of this study was $\alpha=.911$.

\section{Active listening attitude scale (ALAS)}

To assess mothers' listening attitude, we used the ALAS developed by Mishima et al. [20]. The ALAS comprises two subscales and 20 items: listening attitude (10 items) and listening skills (10 items). Each item was scored from 0 to 3 . The higher the score, the better the listening attitude or skill. We obtained the authors' permission to use this scale. The Cronbach's $\alpha$ of this study was $\alpha=.855$.

\section{Beck depression inventory - second edition (BDI-II)}

To assess mothers' depression within the last 2 weeks, we used the Japanese version (by Kojima et al.) [21] of the BDI-II developed by Beck et al. [22]. The BDI-II is a 21item self-report scale that assesses the presence and severity of depressive symptoms. Each item is rated on a 4point scale ranging from 0 to 3 ; the higher the score, the more severe the depressive symptoms. As shown by two previous studies, the BDI-II is a reliable, internally consistent, and valid scale for assessing depression [22, 23]. The reliability and validity values of the Japanese version are excellent [24]. The Cronbach's $\alpha$ of the Japanese version was 0.87 [21], and in this study, it was $\alpha=.931$.

\section{Kessler psychological distress scale (K6)}

To assess mothers' psychological distress, we used the Japanese version (by Furukawa et al.) [25] of the K6 developed by Kessler et al. [26]. The $\mathrm{K} 6$ is a 6 -item selfreported scale that was developed to screen depression and anxiety disorders based on the Diagnostic and Statistical Manual of Mental Disorders Fourth Edition definitions, and it analyzes patients' symptoms over the last 30 days. Moreover, it can also be used to quantify nonspecific psychological distress [26]. Items are rated from 0 to 4 , and the total score ranges from 0 to 24; the higher the score, the more severe the psychological distress. Two independent studies have analyzed and confirmed the excellent validity of the $K 6$ [26, 27], and a study on its Japanese version confirmed the same validity [25]. The Cronbach's $\alpha$ of the original tool was 0.89 [26], and in this study, it was $\alpha=.869$.

\section{Outcome measures of patients Basic characteristics}

In this study, we used the following to analyze patients' basic sociodemographic characteristics: (1) age, (2) gender, (3) whether the patient receives counseling (if yes, for how many years), (4) whether the patient self-harms (if yes, how often), and (5) whether the patient feels that family members make many comments about the patient's eating behaviors.

\section{Rosenberg self-esteem scale (RSS)}

To assess patients' self-esteem, we used the Japanese version (by Abe et al.) [28] of the RSS [29]. The RSS is a 9item scale, and each item was scored on a scale from 1 to 5 ; the higher the score, the higher the self-esteem. The reliability of the scale was $\alpha=0.83$ and the validity was confirmed [28]. The Cronbach's $\alpha$ of this study was $\alpha=.920$.

\section{ULS}

Patients' loneliness was evaluated by the Japanese version of the ULS [17], the same scale used for mothers' loneliness. The Cronbach's $\alpha$ of this study was $\alpha=.935$.

\section{Youth assertion scale (YAS)}

To assess the patients' degree of assertion, we used the YAS developed by Tamase et al. [30]. The YAS comprises two subscales and 16 items: relationship formation (8 items) and persuasion and negotiation (8 items). Each item was scored from 1 to 5 ; the higher the score, the more assertive the person's behaviors. The Cronbach's $\alpha$ of the original study was $\alpha=.80$ for relationship formation and .71 for persuasion negotiation; for this study, it was $\alpha=.832$. The validity of the scale has also been confirmed [30].

\section{Family assessment device (FAD)}

To assess patients' family functioning, we used the Japanese version (by Saeki et al.) [31] of the FAD developed by Epstein et al. [32]. The FAD is used to evaluate a family system based on the McMaster Model of Family Functioning, and it comprises seven subscales: problem solving (5 items), communication (6 items), roles (8 items), affective responsiveness (6 items), affective involvement (7 items), behavior control ( 9 items), and general function (12 items). In this regard, Ridenour et al. reported that best use of the FAD is using the General Functioning Subscale (12 items) as a summary score [33]. As the total number of question items was too large, we used only the General Functioning subscale: the General Functioning subscale had high internal consistency [33], and was used in another study [34]. Each item was scored from 1 to 4; the higher the score, the poorer the family functioning. The Cronbach's $\alpha$ of the General Functioning subscales in the original study was $\alpha=.92$ [32], in another study, $\alpha=.85$ [34], and in this study, $\alpha=.925$.

\section{Eating disorder inventory (EDI)}

To assess patients' eating disorder symptom severity, we used the Japanese version (by Kiriike et al.) [35] of the EDI developed by Garner et al. [36]. The EDI is used to comprehensively evaluate the eating behaviors and 
psychological characteristics of patients with anorexia nervosa and bulimia nervosa, and comprises eight subscales with 64 items: drive for thinness (7 items), bulimia (7 items), body dissatisfaction ( 9 items), ineffectiveness (10 items), perfectionism (6 items), interpersonal distrust (7 items), interoceptive awareness (10 items), and maturity fears (8 items). Each item was scored from 0 to 3 ; the higher the score, the more severe the patient feels the symptoms of their eating disorder are. The Cronbach's $\alpha$ for each subscale was $\alpha=0.60-0.91$, indicating high retest reliability [36].

\section{Statistical analysis}

Descriptive data analysis was conducted by calculating median and mean scores and standard deviation. To find out if the status of mothers and patients differs between high and low social support groups, we divided the mothers into two groups based on the cutoff score for the SPS-10, which was 30 (i.e., if greater than or equal to 30 , high-score group; if lower than 30 , low-score group). As previous studies had used a cutoff SPS-10 score of 30 with valid results, the same point was used in this study [37]. Then, we compared mothers' GSES, ULS, ALAS, BDI-II, and K6 scores as well as patients' RSS, ULS, YAS, FAD, and EDI scores between the high- and low- scoring groups using unpaired t-tests, with $p<0.05$ as significant. As the mother and patient were paired, the patient status was also compared between those groups to assess the impact of social support for the mother on the patient. Statistical analysis was performed using SPSS Statistics version 22 .

\section{Results}

\section{Participants' characteristics}

The study sample comprised 57 pairs: patients with an eating disorder and their mothers. The mean ages were $54.7 \pm 6.6$ years for mothers and $24.5 \pm 6.9$ years for patients. All patients were female. The patient's eating disorder duration reported by her mother was $7.6 \pm 5.3$ years.

Table 1 summarizes the mothers' baseline characteristics and scores. Baseline characteristics were obtained from 56 mothers. Most mothers received some support such as family self-help group, counseling, and/or cooperation with fathers. The mothers' BDI-II was slightly higher than the normal Japanese sample [21], but their K6 was under the optimum cutoff of 12/13 for detecting serious mental illness [26]. The average scores for loneliness and the GSES were almost the same as those of the general population $[16,17]$.

Table 1 Baseline characteristics and scores for the instruments for mothers of patients with eating disorders

\begin{tabular}{|c|c|c|c|c|c|}
\hline \multicolumn{2}{|l|}{ Questionnaire or Scale } & \multirow{2}{*}{$\begin{array}{l}\mathbf{n} \\
43\end{array}$} & \multirow{2}{*}{$\begin{array}{l}\% \\
75.4\end{array}$} & \multirow{2}{*}{$\begin{array}{c}\text { mean } \\
6.5\end{array}$} & \multirow{2}{*}{$\frac{S D}{6.0}$} \\
\hline Mother's confirmation of the patient being under medical care (if yes, years) & Yes & & & & \\
\hline & No & 13 & 22.8 & & \\
\hline \multirow[t]{3}{*}{ Mother's experience with counseling } & Currently receiving & 9 & 15.8 & & \\
\hline & Received in the past & 24 & 42.1 & & \\
\hline & Never & 23 & 40.4 & & \\
\hline \multirow[t]{3}{*}{ Mother's past history of eating disorder } & Yes & 2 & 3.5 & & \\
\hline & No & 52 & 91.2 & & \\
\hline & Unknown & 2 & 3.5 & & \\
\hline \multirow[t]{4}{*}{ Mother's feeling that the mother is cooperating with the father to handle the patient } & Yes & 31 & 54.4 & & \\
\hline & No & 6 & 10.5 & & \\
\hline & Neither consent nor denial & 15 & 26.3 & & \\
\hline & Not applicable & 4 & 7.0 & & \\
\hline \multirow[t]{3}{*}{ Mother's experience with joining a family self-help group } & Yes & 38 & 66.7 & & \\
\hline & Joined in the past & 13 & 22.8 & & \\
\hline & Never & 4 & 7.0 & & \\
\hline SPS-10 & & 57 & & 30.8 & 4.9 \\
\hline GSES & & 57 & & 7.1 & 4.1 \\
\hline ULS & & 55 & & 39.2 & 9.7 \\
\hline ALAS & & 56 & & 36.1 & 7.0 \\
\hline BDI-II & & 57 & & 13.9 & 10.4 \\
\hline K6 & & 56 & & 6.9 & 4.5 \\
\hline
\end{tabular}

SPS-10 Social Provisions Scale Japanese version, GSES General Self-Efficacy Scale, ULS University of California, Los Angeles Loneliness Scale, ALAS Active Listening Attitude Scale; Los Angeles Loneliness Scale, BDI-II Beck Depression Inventory-Second Edition, K6 Kessler Psychological Distress Scale 
Table 2 summarizes patient scores for each of the instruments used. The average RSS score was considerably lower than the average score of Japanese female university students [28]. The average YAS score was considerably lower than the average score of Japanese university students [30]. Regarding FAD, the total score for the 12 items of the General Functioning subscale was much higher than the average of Japanese university students and their families [31]. Unsurprisingly, the patient's family functioning was considered to be impaired.

\section{Comparison between the mothers' high- and low-score groups for SPS-10}

The mothers' average score on the SPS-10 was 30.8 $(\mathrm{SD}=4.9)$. High-score groups consisted of 34 mothers who scored greater than or equal to 30 , and the lowscore group consisted of 23 mothers who scored lower than 30. Table 3 shows a comparison of the mothers' scores for each instrument. Mothers in the low-score group had significantly higher scores for the ULS ( $p<$ $0.01)$ and the BDI-II $(p<0.05)$ compared to those of the high-score group; namely, mothers who experienced less social support were shown to have greater loneliness and depressive symptoms. Mothers in the low-score group had higher scores for the K6 and lower scores for the ALAS and GSES than the high-score group, but there were no significant differences in the scores on the ALAS, K6, and GSES between the groups.

Table 4 shows a comparison of patients' scores by mothers' group. Twenty-eight patients were in the highscoring group and 27 were in the low-scoring group based on their mothers' SPS-10 score. All patients answered the EDI, but for ULS, RSS, and YAS, one from the low-scoring group did not respond, and for the FAD, one from the high-scoring group did not respond. The patients' average ULS and FAD scores were higher in the high-score mothers' group, and the patients' average RSS and YAS total scores were higher in the mothers' low-score group: however, both pairs of scores were not significantly different. On the EDI subscale, there were no significant differences between the high-scoring mothers' group and low-scoring mothers' group. In general, the amount of support the mother felt did not seem to be significantly associated with patients' symptoms.

Table 2 Baseline characteristics and scores of the instruments applied to patients with eating disorders

\begin{tabular}{|c|c|c|c|c|c|c|}
\hline \multicolumn{3}{|l|}{ Questionnaire or Scale } & \multirow{2}{*}{$\frac{\mathbf{n}}{22}$} & \multirow{2}{*}{$\frac{\%}{38.6}$} & \multirow[t]{2}{*}{ Mean } & \multirow[t]{2}{*}{ SD } \\
\hline Receiving counseling (if yes, years) & Yes & & & & & \\
\hline & No & & 35 & 61.4 & & \\
\hline \multirow[t]{5}{*}{ Self-harms } & Yes & Almost every day & 0 & 0 & & \\
\hline & & About 2-3 times a week & 2 & 3.5 & & \\
\hline & & About 2-3 times a month & 1 & 1.8 & & \\
\hline & & Other & 3 & 5.3 & & \\
\hline & No & & 51 & 89.5 & & \\
\hline \multirow[t]{4}{*}{ Feeling that family members make many comments about the patient's eating behaviors } & Many & y comments & 10 & 17.5 & & \\
\hline & If any & ything, some & 19 & 33.3 & & \\
\hline & If any & ything, few & 17 & 29.8 & & \\
\hline & Few & & 11 & 19.3 & & \\
\hline RSS & & & 56 & & 19.5 & 8.5 \\
\hline ULS & & & 56 & & 50.1 & 12.4 \\
\hline YAS & & & 56 & & 44.9 & 8.5 \\
\hline FAD & & & 56 & & 29.3 & 7.6 \\
\hline EDI-Total & & & 57 & & 92.1 & 37.5 \\
\hline EDI-drive for thinness & & & 57 & & 11.8 & 6.8 \\
\hline EDI-bulimia & & & 57 & & 8.5 & 6.9 \\
\hline EDI-body dissatisfaction & & & 57 & & 14.8 & 7.7 \\
\hline EDI-ineffectiveness & & & 57 & & 15.8 & 7.8 \\
\hline EDI-perfectionism & & & 57 & & 7.8 & 4.3 \\
\hline EDI-interpersonal distrust & & & 57 & & 8.3 & 4.1 \\
\hline EDI-interoceptive awareness & & & 57 & & 14.7 & 7.3 \\
\hline EDI-maturity fears & & & 57 & & 10.3 & 5.6 \\
\hline
\end{tabular}


Table 3 Comparison of the scores on each of the instruments by two different groups of mothers

\begin{tabular}{|c|c|c|c|c|c|c|c|}
\hline \multirow[t]{2}{*}{ Scale } & \multicolumn{3}{|c|}{ High-score mothers' group ${ }^{a}$} & \multicolumn{3}{|c|}{ Low-score mothers' group ${ }^{a}$} & \multirow[t]{2}{*}{$p$} \\
\hline & $n$ & Mean & SD & $n$ & Mean & SD & \\
\hline GSES & 34 & 7.4 & 4.1 & 23 & 6.7 & 4.1 & .547 \\
\hline ULS & 33 & 33.8 & 6.4 & 22 & 47.1 & 8.1 & $.000^{* *}$ \\
\hline ALAS & 34 & 36.9 & 8.2 & 22 & 34.8 & 4.5 & .276 \\
\hline BDI-II & 34 & 11.0 & 8.4 & 23 & 18.0 & 11.7 & $.011^{*}$ \\
\hline K6 & 34 & 6.4 & 4.1 & 22 & 7.7 & 5.1 & .295 \\
\hline
\end{tabular}

ULS University of California, Los Angeles Loneliness Scale, ALAS Active Listening Attitude Scale, BDI-II Beck Depression Inventory-Second Edition, K6 Kessler Psychological Distress Scale, GSES General Self-Efficacy Scale

${ }^{\text {a }}$ The groups were divided based on the mother's score being greater than/equal to or lower than 31 points on the Social Provisions Scale Japanese version (SPS-10)

\section{Discussion}

In this study, we investigated how social support for mothers who are caregivers of patients with eating disorders is associated with maternal mental status and patients' symptomatic severity. Our results showed that mothers who felt that they received higher levels of social support felt less isolated and less depressed than those that felt that they received lower levels of social support. However, there were no significant differences in listening attitude, self-efficacy, or psychological distress between mothers who felt that they received high levels of social support and those who felt that they received low levels of social support.

Coomber et al. reported that social support was not a significant predictor of burden or psychological distress among caregivers of people with eating disorders [10]. In our study, mothers in the low-score group for the SPS10 had significantly higher scores for the BDI-II than did the high-score group for the SPS-10, but there were no significant differences in the scores for the K6 evaluating psychological distress. Although there were distinct differences in scales and measurement methods between our study and previous studies, our results were consistent with the finding that social support did not predict psychological stress. Dimitropoulos et al. reported that decreased social support predicted increased family dysfunction but not psychological distress, and that family dysfunction was correlated with high levels of burden in caregivers of patients with anorexia nervosa [8]. This is similar to the results of our study, in which there was no significant difference in the scores of $\mathrm{K} 6$ between mothers receiving high levels of social support and those receiving low levels of social support. However, as shown in Table 4, in our study there were no differences in patients' family functioning between mothers receiving high levels of social support and those receiving low

Table 4 Comparison of patient scores for mothers in the high-score and low-score groups

\begin{tabular}{|c|c|c|c|c|c|c|c|}
\hline \multirow[t]{2}{*}{ Scale } & \multicolumn{3}{|c|}{ High-score mothers' group ${ }^{a}$} & \multicolumn{3}{|c|}{ Low-score mothers' group ${ }^{a}$} & \multirow[t]{2}{*}{$p$} \\
\hline & $\mathrm{n}$ & Mean & SD & $\mathrm{n}$ & Mean & SD & \\
\hline ULS & 33 & 50.8 & 11.7 & 23 & 49.1 & 13.4 & .604 \\
\hline RSS & 33 & 18.2 & 7.8 & 23 & 21.5 & 9.2 & .144 \\
\hline YAS & 33 & 44.4 & 7.7 & 23 & 45.7 & 9.6 & .555 \\
\hline FAD & 33 & 29.7 & 6.8 & 23 & 28.8 & 8.8 & .663 \\
\hline EDI-Total & 34 & 92.0 & 34.8 & 23 & 92.2 & 41.9 & .984 \\
\hline EDI-drive for thinness & 34 & 11.8 & 6.5 & 23 & 11.7 & 7.2 & .945 \\
\hline EDI-bulimia & 34 & 8.4 & 6.9 & 23 & 8.7 & 7.0 & .861 \\
\hline EDI-body dissatisfaction & 34 & 14.8 & 7.3 & 23 & 14.8 & 8.3 & .999 \\
\hline EDI-ineffectiveness & 34 & 16.4 & 7.6 & 23 & 14.9 & 8.2 & .475 \\
\hline EDI-perfectionism & 34 & 7.4 & 4.2 & 23 & 8.4 & 4.5 & .386 \\
\hline EDI-interpersonal distrust & 34 & 8.2 & 3.5 & 23 & 8.5 & 4.9 & .757 \\
\hline EDI-interoceptive awareness & 34 & 14.6 & 7.0 & 23 & 14.8 & 7.8 & .893 \\
\hline EDI-maturity fears & 34 & 10.3 & 5.5 & 23 & 10.2 & 6.0 & .945 \\
\hline
\end{tabular}

ULS University of California, Los Angeles Loneliness Scale, RSS Rosenberg Self-Esteem Scale, YAS youth assertion scale, EDI Eating Disorder Inventory, FAD Family Assessment Device

${ }^{a}$ The groups were divided based on the mother's score being greater than/equal to or lower than 31 points on the Social Provisions Scale Japanese version (SPS-10) 
levels of social support. We believe the difference between our results and those of the cited study may be due to family functioning in our study being based on patients' self-reports, not the mothers'. Martin et al. reported that being married was a protective factor with regard to caregiver burden for mothers, but their research merely investigated marital status, not whether mothers felt supported [7]. Our study investigated mothers' feelings of support, but did not specify who provided it. In our study, the percentage of mothers (from both groups) who could cooperate with fathers was $54.4 \%$, suggesting that they might be receiving support from fathers.

Therefore, there were no differences in the level of psychological stress between mothers who are caregivers of patients with eating disorders who feel that they receive substantial social support and those who do not. However, our study findings showed that their loneliness and depression might be alleviated by social support, as revealed by their scores.

Additionally, our results showed that there were no differences in patients' loneliness, self-esteem, degree of assertion, family functioning, or eating disorder symptom severity levels when comparing patients who were cared for by mothers receiving high levels of social support and those who were cared for by mothers who received low levels of social support.

Contrary to our findings, Ohara et al. have shown that mothers receiving social support provide self-assessed reports stating that their care recipients have lower symptom severity [1]. We believe the difference between our results and those of the cited study may owe to symptomatic severity in our study being based on patients' selfreports, not their mothers'. In corroboration with our findings, Rhind et al.'s study found no association between caregivers' social support and patients' self-assessments of their eating disorder symptom severity [11].

We believe our results and the similar results of this cited study may be owing to mothers who receive more social support being more likely to underestimate their care recipients' symptomatic severity, which may not concur with patients' self-assessments on the same topic. Thus, regardless of whether mothers who are caregivers for patients with eating disorders feel that they receive social support, there are no differences in the patients' view of loneliness, severity of symptoms, assertions, and family functioning do not appear to change significantly.

\section{Study strengths}

Our study had several strengths: first, it targeted not only the mothers who are caregivers of patients with eating disorders, but also the patients themselves. While most previous studies have evaluated patients' symptoms from the caregivers' point of view $[1,7,10,38]$ with the exception of one study [11], ours provided patients' self- assessments regarding their symptoms. This methodological approach made it possible for our analyses to demonstrate whether caregivers' social support was associated with patients.

Second, participants comprised both caregivers of patients who are outpatients at a hospital and caregivers who participate in a local family association in the community (not the hospital). It represents a wider range of patients, including those who do not need medical care and those who refuse medical care, as well as those who receive medical care.

Third, this study measured factors other than caregivers' social support (e.g., self-efficacy, loneliness, and depression) as well as patient factors (e.g., patients' loneliness and degree of assertion). As a result, we were able to show that social support for caregivers was related to low isolation and low depression of caregivers, but not to psychological stress, self-efficacy, or listening attitudes of caregivers. Furthermore, we were able to show that social support for caregivers was not related to the severity of symptoms felt by the patient. Given that there is no established model for how social support affects the depression and care burden of mothers who are caregivers of patients with eating disorders, we hope that the results of this study will help clarify the issue.

\section{Limitations}

First, this was a cross-sectional study. Therefore, our results alone cannot show causal relationships; that is, our results do not allow for the final conclusion that social support does not affect patients' symptoms. It is merely demonstrated that maternal social support is not associated with a reduction in patient symptoms.

Second, we had a small sample size. This may have resulted in the small effects we observed, subsequently not allowing for the detection of any significant differences among the studied variables.

Third, we did not identify or differentiate any subgroups of eating disorders, and the participating patients' age range was wide. Some previous studies targeted only anorexia patients $[1,8]$, and another restricted its sample to adolescents [39]. Moreover, it has been reported that compared to caregivers of bulimia patients, caregivers of anorexia patients experienced a higher amount of problems in three areas: "not enough information on rehabilitation," "problems caused by relapses or crises," and "depression, anxiety, burn-out, physical illness of the carer [40]." Thus, we believe that future studies should distinguish patients by type of eating disorder, as different types seem to evoke different outcomes for the caregivers.

Fourth, this study measured mothers' social support through the SPS-10, but previous studies have used other scales; for example, social support was measured 
by the Social Provisions Scale [8], the Social Network Questionnaire [1], the Social Support Questionnaire [10] and the Oslo three-item social support [11]. Therefore, it is difficult to directly compare the content and amount of social support with other studies.

Fifth, we measured patients' eating disorder symptom severity through the EDI, but we did not check the patient's diagnosis of eating disorders or overall severity such as disorders in daily life or body weight. Therefore, this study may only evaluate one aspect of the patient's symptoms.

\section{Recommendations}

Based on these limitations, we believe that future studies are warranted to clarify the mechanism by which social support affects patients with eating disorders and their caregivers. Additionally, future studies on the topic should have larger samples, subdivide eating disorders by type (e.g., anorexia versus bulimia), divide patients by age, divide the social support construct into more subfactors, and include caregivers who do not receive appropriate amounts of support. Finally, further relevant factors should be posited, so as to allow for the development of a model that delineates the mechanisms behind these studied variables. This model may enable practitioners to improve patients' symptoms and maternal/caregivers' depression through the provision of interventions tailored to patients with eating disorders and to their caregivers.

\section{Conclusions}

This study aimed to investigate how social support for mothers who are caregivers of patients with eating disorders improves their mental status and, consequently, the symptoms and status of the patients. High social support for mothers of patients with eating disorders was significantly associated with lower loneliness and depression of the mothers. However, there were no significant differences in the symptoms and status of the patients by comparing based on mothers' level of social support.

\begin{abstract}
Abbreviations
ALAS: Active Listening Attitude Scale; BDI-II: Beck Depression Inventory; EDI: Eating Disorder Inventory; FAD: Family Assessment Device; GSES: General Self-Efficacy Scale; K6: Kessler Psychological Distress Scale; RSS: Rosenberg Self-Esteem Scale; SPS: The Social Provisions Scale; SPS-10: The Social Provisions Scale-10 item; ULS: University of California, Los Angeles Loneliness
\end{abstract} Scale; YAS: Youth Assertion Scale

\section{Acknowledgments}

The authors wish to thank Takao Suzuki of the family support group of eating disorders "Pokoapoko" for his support. We thank all study participants.

\section{Authors' contributions}

FK, AY, HS, and NW designed the study. AY wrote the manuscript. FK and AY conducted recruitment and data collection. NW, MK, and AT supervised the study and edited various drafts of the manuscript. All authors have read and approved the final manuscript.

\section{Funding}

This study was supported by a Grant-in-Aid for Scientific Research KAKENHI Grant Numbers 16 K12256 from the Japanese Ministry of Education, Science, and Technology.

\section{Availability of data and materials}

The datasets used and/or analyzed during the current study are available from the corresponding author on reasonable request.

\section{Ethics approval and consent to participate}

This study was approved by the Ethics Review Committee of Nagoya City University Graduate School of Medical Sciences, Japan (Ref: No 60-17-0001). All participants provided written informed consent to the study.

\section{Consent for publication}

Not applicable.

\section{Competing interests}

FK received speaker's fees from Otsuka Pharmaceutical Co., Ltd. AY received medical fees from Gifu Hospital, speaker's fees from Aichi Education and Sports foundation, Kyowa Pharmaceutical Industry Co., Ltd., Meiji Seika Pharma Co., Ltd., Mental Care Association Japan, Mochida Pharmaceutical Co., Ltd., Otsuka Pharmaceutical Co., Ltd., Shionogi \& Co., Ltd., and other fees from Nagoya City. AY received grants from the Japanese Ministry of Education, Science, and Technology. HS declares no conflicts of interest. MK reports a grant from the Japanese Ministry of Education, Science, and Technology, grants from Novartis Pharma K.K., personal fees from Shinogi \& Co., Ltd., and personal fees from Yoshitomiyakuhin Corporation, outside the submitted work. TA has received lecture fees from Astellas Pharma Inc., AstraZeneca K.K., Daiichi Sankyo Co., Ltd., Sumitomo Dainippon Pharma Co., Ltd., Eisai Co., Ltd., Hisamitsu Pharmaceutical Co., Inc., Janssen Pharmaceutical K.K., Kyowa Kirin Co., Ltd., Kyowa Pharmaceutical Industry Co., Ltd., Eli Lilly Japan K.K., MSD K.K., Meiji Seika Pharma Co., Ltd., Mochida Pharmaceutical Co., Ltd., Mundipharma K.K., Nipro, Otsuka Pharmaceutical Co. Ltd., Pfizer Japan Inc., Shionogi \& Co., Ltd., Terumo, and Tsumura \& Co., Ltd. TA has received research funds from Daiichi Sankyo Co., Ltd., Eisai Co., Ltd., FUJIFILM RI Pharma Co., Ltd., Eli Lilly Japan K.K., MSD K.K., Novartis Pharma K.K., Otsuka Pharmaceutical Co., Ltd., Shionogi \& Co., Ltd., and Mitsubishi Tanabe Pharma Corporation. NW has received royalties from Sogensha, Medical View, and Advantage Risk Management for writings.

\section{Author details}

${ }^{1}$ Department of Psychiatry and Cognitive-Behavioral Medicine, Nagoya City University Graduate School of Medical Sciences, Nagoya, Japan. ${ }^{2}$ Department of Psychiatric and Mental Health Nursing, Nagoya City University Graduate School of Nursing, 467-8601, 1 Kawasumi, Mizuho-cho, Mizuho-ku, Nagoya, Japan. ${ }^{3}$ Department of Health Promotion and Human Behavior, Kyoto University Graduate School of Medicine/School of Public Health, Kyoto, Japan.

Received: 19 September 2020 Accepted: 9 December 2020 Published online: 06 January 2021

\section{References}

1. Ohara C, Komaki G, Yamagata Z, Hotta M, Kamo T, Ando T. Factors associated with caregiving burden and mental health conditions in caregivers of patients with anorexia nervosa in Japan. Biopsychosoc Med. 2016;10:21.

2. Martin J, Padierna A, Aguirre U, Quintana JM, Hayas CL, Munoz P. Quality of life among caregivers of patients with eating disorders. Qual Life Res. 2011; 20(9):1359-69.

3. Gonzalez N, Padierna A, Martin J, Aguirre U, Quintana JM. Predictors of change in perceived burden among caregivers of patients with eating disorders. J Affect Disord. 2012;139(3):273-82.

4. Kyriacou O, Treasure J, Schmidt U. Expressed emotion in eating disorders assessed via self-report: an examination of factors associated with expressed emotion in carers of people with anorexia nervosa in comparison to control families. Int J Eat Disord. 2008;41(1):37-46.

5. Stefanini MC, Troiani MR, Caselli M, Dirindelli P, Lucarelli S, Caini S, et al. Living with someone with an eating disorder: factors affecting the caregivers' burden. Eat Weight Disord. 2019;24(6):1209-14. 
6. Anastasiadou D, Medina-Pradas C, Sepulveda AR, Treasure J. A systematic review of family caregiving in eating disorders. Eat Behav. 2014;15(3):464-77.

7. Martin J, Padierna A, Aguirre U, Gonzalez N, Munoz P, Quintana JM. Predictors of quality of life and caregiver burden among maternal and paternal caregivers of patients with eating disorders. Psychiatry Res. 2013; 210(3):1107-15.

8. Dimitropoulos G, Carter J, Schachter R, Woodside DB. Predictors of family functioning in carers of individuals with anorexia nervosa. Int J Eat Disord. 2008;41(8):739-47.

9. Fisher CA, Skocic S, Rutherford KA, Hetrick SE. Family therapy approaches for anorexia nervosa. Cochrane Database Syst Rev. 2019;5:CD004780.

10. Coomber K, King RM. Coping strategies and social support as predictors and mediators of eating disorder carer burden and psychological distress. Soc Psychiatry Psychiatr Epidemiol. 2012;47(5):789-96.

11. Rhind C, Salerno L, Hibbs R, Micali N, Schmidt U, Gowers S, et al. The objective and subjective caregiving burden and caregiving Behaviours of parents of adolescents with anorexia nervosa. Eur Eat Disord Rev. 2016;24(4): 310-9.

12. Cutrona CE, Russell D. The provision of social relationship and adaptation to stress. Adv Personal Relationships. 1987;1:37-67.

13. lapichino E, Rucci P, Corbani IE, Apter G, Quartieri Bollani M, Cauli G, et al. Development and validation of an abridged version of the social provisions scale (SPS-10) in Italian. J Psychopathol. 2016;22:157-63.

14. Katsuki F, Yamada A, Kondo M, Sawada H, Watanabe N, Akechi T, et al. Development and validation of the 10-item Social Provisions Scale (SPS-10) Japanese version. Nagoya Medical Journal. in press.

15. Sakano Y, Tohjoh M. The General Self/Efficay Scale (GSES) : Scale development and validation. Japanese Assoc Behav Cogn Ther. 1986;12:7382.

16. Sakano Y. Verification of Validity of General Self-Efficacy Scale (GSES). Waseda J Hum Sci. 1989;2:91-8.

17. Moroi K. Dimensions of the revised UCLA Loneliness Scale Annual reports of Departments of Social \& Human Studies and Language \& Literature, vol. 42; 1992. p. 23-51.

18. Russell DW. UCLA loneliness scale (version 3): reliability, validity, and factor structure. J Pers Assess. 1996;66(1):20-40.

19. Moroi K. Loneliness and self-consciousness in high-school students the Japanese journal of. Psychology. 1985;56(4):237-40.

20. Mishima N, Kubota S, Nagata S. The development of a questionnaire to assess the attitude of active listening. J Occup Health. 2000;42:111-8.

21. Kojima M, Furukawa TA, Takahashi H, Kawai M, Nagaya T, Tokudome S. Cross-cultural validation of the Beck depression inventory-ll in Japan. Psychiatry Res. 2002;110(3):291-9.

22. Beck AT, Steer RA, Brown GK. Manual for the Beck depression inventory second edition (BDI-II). San Antonia: The Psychological corporation; 1996.

23. Arnau RC, Meagher MW, Norris MP, Bramson R. Psychometric evaluation of the Beck depression inventory-II with primary care medical patients. Health Psychol. 2001;20(2):112-9.

24. Hiroe T, Kojima M, Yamamoto I, Nojima S, Kinoshita Y, Hashimoto N, et al. Gradations of clinical severity and sensitivity to change assessed with the Beck depression inventory-II in Japanese patients with depression. Psychiatry Res. 2005;135(3):229-35.

25. Furukawa TA, Kawakami N, Saitoh M, Ono Y, Nakane Y, Nakamura Y, et al. The performance of the Japanese version of the K6 and K10 in the world mental health survey Japan. Int J Methods Psychiatr Res. 2008;17(3):152-8.

26. Kessler RC, Barker PR, Colpe LJ, Epstein JF, Gfroerer JC, Hiripi E, et al. Screening for serious mental illness in the general population. Arch Gen Psychiatry. 2003;60(2):184-9.

27. Furukawa TA, Kessler RC, Slade T, Andrews G. The performance of the K6 and K10 screening scales for psychological distress in the Australian National Survey of mental health and well-being. Psychol Med. 2003;33(2):357-62.

28. Abe M, Konno H. Development of state self-esteem scale. Japanese J Pers. 2007;16(1):36-46.

29. Rosenberg M. Society and the adolescent self-image. Princeton: Princeton University press; 1965.

30. Tamase K, Ochi T, Sainou C, Ishikawa M. Development of an assertion scale for adolescents and its reliability and validity. Bull Nara Univ Educ Cult Soc Sci. 2001;50(1):221-32.

31. Saeki T, Asukai N, Miyake Y, Miguchi M, Yamawaki S. Reliability and validity of the Japanese version of the family assessment device (FAD). Arch Psychiatr Diag Clin Eval. 1997;8:181-92.
32. Epstein NB, Baldwin LM, Bishop DS. The McMaster family assessment device J Marital Fam Ther. 1983;9(2):171-80.

33. Ridenour TA, Daley JG, Reich W. Factor analyses of the family assessment device. Fam Process. 1999;38(4):497-510.

34. Hausken SES, Lie HC, Lien N, Sleddens EFC, Melbye EL, Bjelland M. The reliability of the general functioning scale in Norwegian 13-15-year-old adolescents and association with family dinner frequency. Nutr J. 2019;18(1):20.

35. Kiriike N. Eating disorders: don't eat, can't eat, don't stop eating. 2nd edition ed. Igakushoin: Tokyo; 2000.

36. Garner DM, Olmstead MP, Polivy J. Development and validation of a multidimensional eating disorder inventory for anorexia nervosa and bulimia. Int J Eat Disord. 1983;2:15-34.

37. Orpana HM, Lang JJ, Yurkowski K. Validation of a brief version of the social provisions scale using Canadian national survey data. Health Promot Chronic Dis Prev Can. 2019;39(12):323-32.

38. McEvoy PM, Targowski K, McGrath D, Carter O, Fursland A, Fitzgerald M, et al. Efficacy of a brief group intervention for carers of individuals with eating disorders: a randomized control trial. Int J Eat Disord. 2019;52(9):987-95.

39. Haynos AF, Watts AW, Loth KA, Pearson CM, Neumark-Stzainer D. Factors Predicting an Escalation of Restrictive Eating During Adolescence. J Adolesc Health. 2016;59(4):391-6.

40. Graap H, Bleich S, Herbst F, Trostmann Y, Wancata J, de Zwaan M. The needs of carers of patients with anorexia and bulimia nervosa. Eur Eat Disord Rev. 2008;16(1):21-9.

\section{Publisher's Note}

Springer Nature remains neutral with regard to jurisdictional claims in published maps and institutional affiliations.

\section{Ready to submit your research? Choose BMC and benefit from:}

- fast, convenient online submission

- thorough peer review by experienced researchers in your field

- rapid publication on acceptance

- support for research data, including large and complex data types

- gold Open Access which fosters wider collaboration and increased citations

- maximum visibility for your research: over $100 \mathrm{M}$ website views per year

At BMC, research is always in progress.

Learn more biomedcentral.com/submissions 